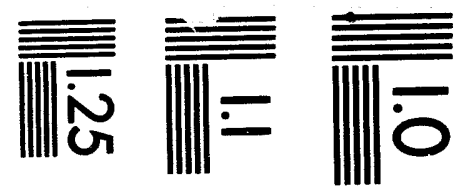

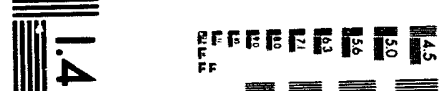

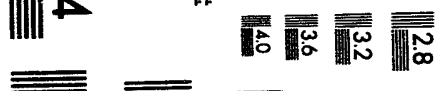

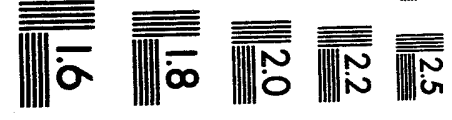



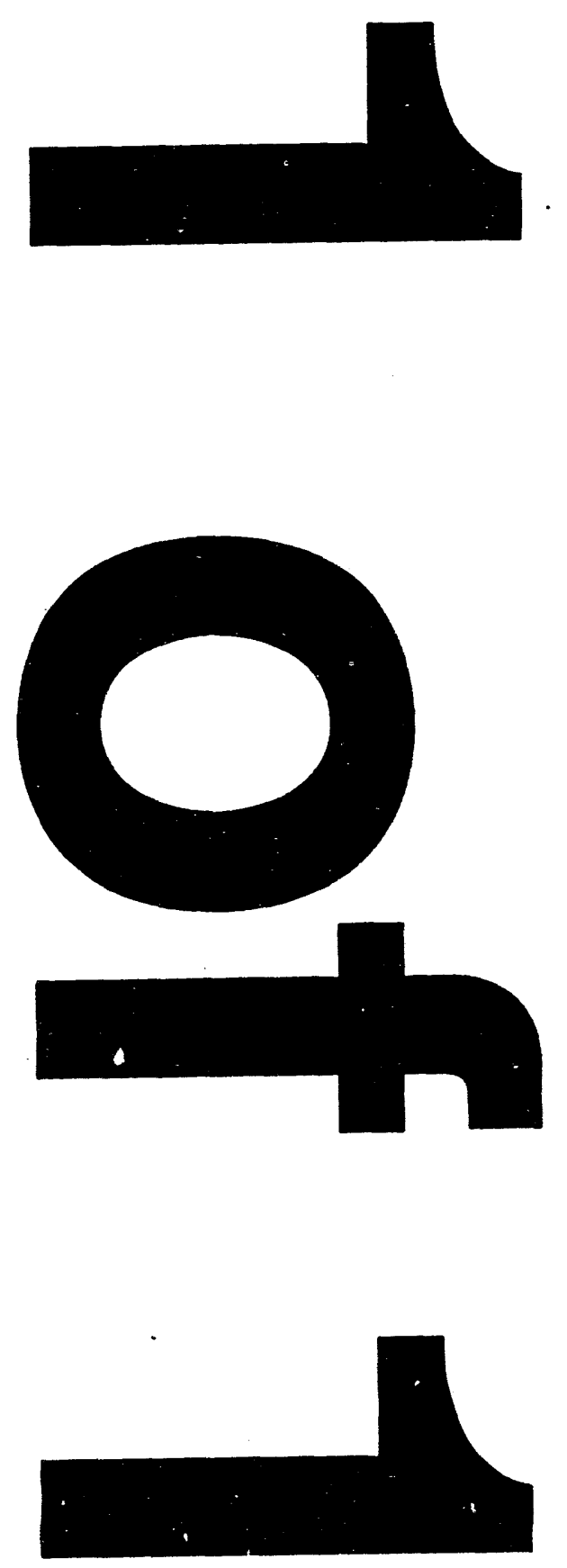
IS-5089

UC-15

\title{
OPTICAL ASSAY TECHNOLOGY FOR SAFEGUARDS
}

M.C. EDELSON, S.C. LEE, R.J. LIPERT, G.M. MURRAY, R.A. SCHULER, S.J. WEEKS, and Z-M. WANG

\author{
Quarterly Report
}

October 1 - December 31, 1991

Date Transmitted:

December 1992

Prepared for the Office of Safeguards and Security

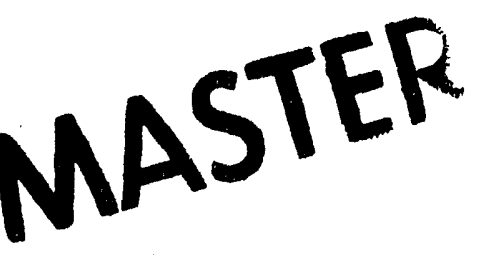




\section{TABLE OF CONTENTS}

TABLE OF CONTENTS ii

ABSTRACT

INTRODUCTION

RESEARCH SUMMARY

1. INDUCTIVELY COUPLED PLASMA - LASER EXCITED ATOMIC 1

FLUORESCENCE SPECTROSCOPY (ICP-LEAFS)

2. MODIFIED HEAT-PIPE OVEN FOR HIGH-TEMPERATURE SPECTROSCOPY 3

3. OPTICAL SPECTROSCOPY OF ACTINIDE IONS IN CONDENSED PHASES 10

4. APPLICATIONS OF DIODE LASERS 11

$\begin{array}{lr}\text { DISTRIBUTION LIST } & 20\end{array}$ 


\begin{abstract}
Research conducted in the Ames Laboratory Nuclear Safeguards and Security Program during the period October 1, 1991 to December 31, 1991 is reviewed.

Current work in applying optical spectroscopy to the determination of actinide and related elements in the gas phase is discussed. The major portion of this report is devoted to a description of a successful modification to a high-temperature heat pipe oven described in a previous report. High-resolution spectra of rare earth elements volatilized in this oven, measured using Doppler-free spectroscopy (i.e., saturated absorption spectroscopy) are presented along with a comparison of the spectrum of samarium measured with Doppler-free and ordinary techniques. Rare earth elements have strong spectral similarities to the actinide elements and it is clear from work that Doppler-free methods applied to the actinides will be very selective and capable of isotopic resolution.
\end{abstract}




\section{INTRODUCTION}

The major portion of this report is devoted to a description of a successful modification to a high-temperature heat pipe oven described in a previous report. High-resolution spectra of rare earth elements volatilized in this oven, measured using Doppler-free spectroscopy (i.e., saturated absorption spectroscopy) are presented along with a comparison of the spectrum of samarium measured with Doppler-free and ordinary techniques (Figure 8). Rare earth elements have strong spectral similarities to the actinide elements and it is clear from work that Doppler-free methods applied to the actinides will be very selective and capable of isotopic resolution.

\section{INDUCTIVELY COUPLED PLASMA - LASER EXCITED ATOMIC FLUORESCENCE SPECTROSCOPY (ICP-LEAFS)}

\section{Purpose:}

To assess the feasibility of ICP-LEAFS for the determination of Pu and its isotopes without the need for chemical separations from matrix elements or the oxidation state adjustment of Pu prior to analysis.

\section{Progress:}

An ultrasonic nebulizer was acquired early in the quarter. After the substitution of the ultrasonic nebulizer for the pneumatic nebulizer previously used for ICP-LEAFS, the measurement of ICP-LEAFS detection limits was repeated using a molybdenum solution. Two of the spectra recorded during this experiment are presented in Figure 1. These spectra and others were used to calculate an ICP-LEAFS detection limit of $17 \mathrm{ppb}$, which is a substantial improvement over detection limits obtained with pneumatic nebulization (524 ppb, see last quarter's report).

Subsequent to the molybdenum experiment, the system was used to measure the detection limit of uranium. Solutions containing ${ }^{235} \mathrm{U}$ were unavailable so solutions of depleted uranium were used. The previous limit of detection for uranium was $524 \mathrm{ppb}$. The spectra in Figure 2 show spectra of uranium solutions containing 10 and $1 \mathrm{ppm}$ 238 U. A detection limit of $369 \mathrm{ppb}$ was calculated from these and other spectra.

A new Nd-YAG laser was installed this quarter. This laser, which has a greater repetition rate $(30 \mathrm{~Hz})$ than the laser it replaced $(20 \mathrm{~Hz})$ and a higher output power, increased the output power obtainable from our dye laser from $<10 \mathrm{~mJ} /$ pulse to 12 $\mathrm{mJ} / \mathrm{pulse}$. This was accomplished by inserting an additional amplifier stage (there are now four such stages) in the dye laser. It is expected that this increase in dye laser power will improve the feasibility of using Raman shifting to increase the wavelength coverage of the dye laser without frequency doubling. The dye laser was enclosed in a plastic case to improve operational safety, dye laser stability, and to reduce the potential for damage of the dye laser optics due to dust. The plastic chosen for the enclosure strongly attenuated the doubled Nd-YAG output (optical density 7). This allowed the laser to be viewed during operation while eliminating any hazard from scattered or reflected Nd-YAG laser light. 


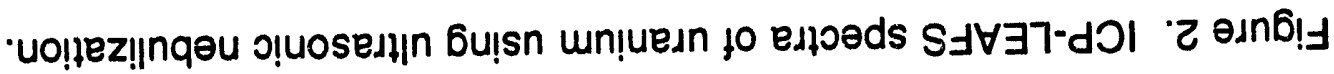
JəqunN fuịod eieg

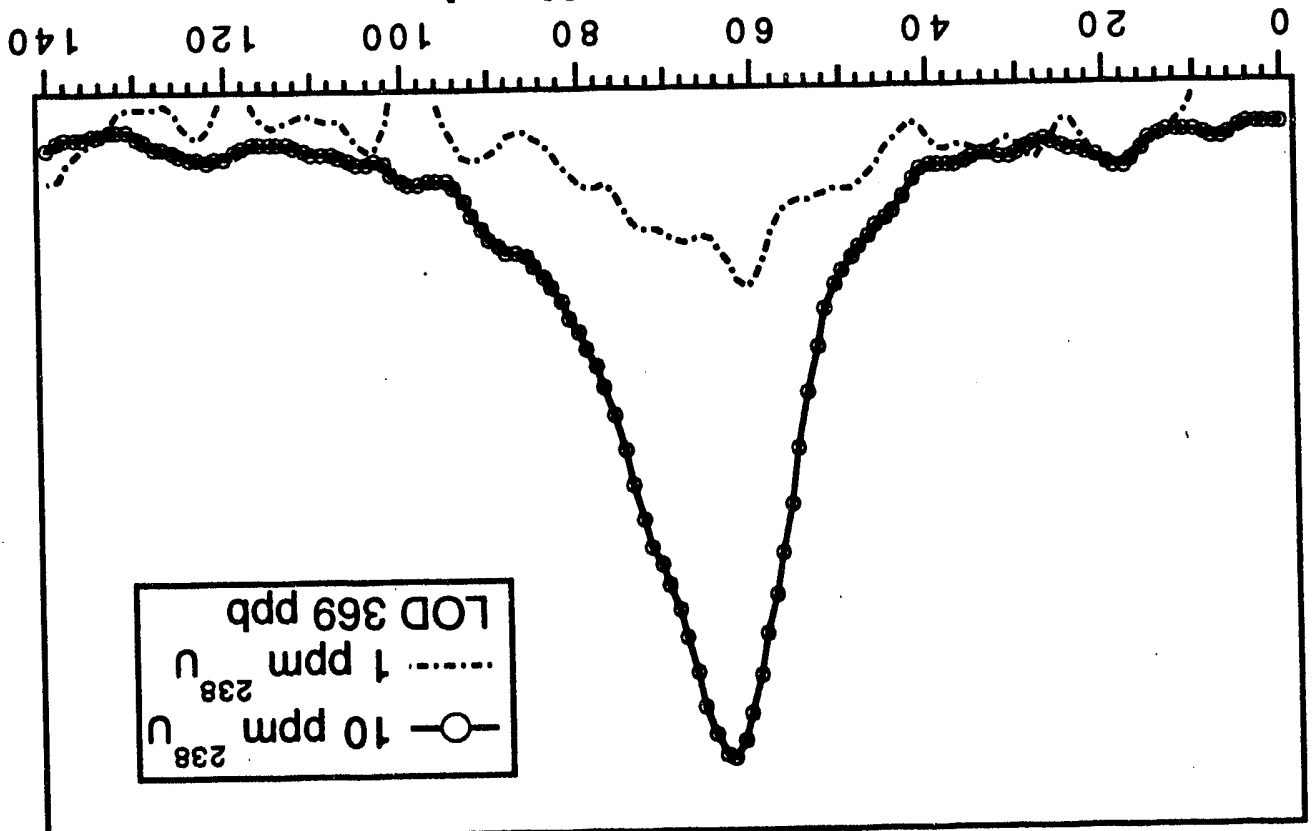

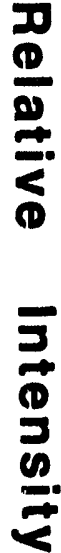

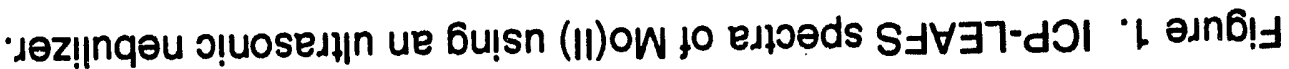

\section{JaquinN juiod efea}

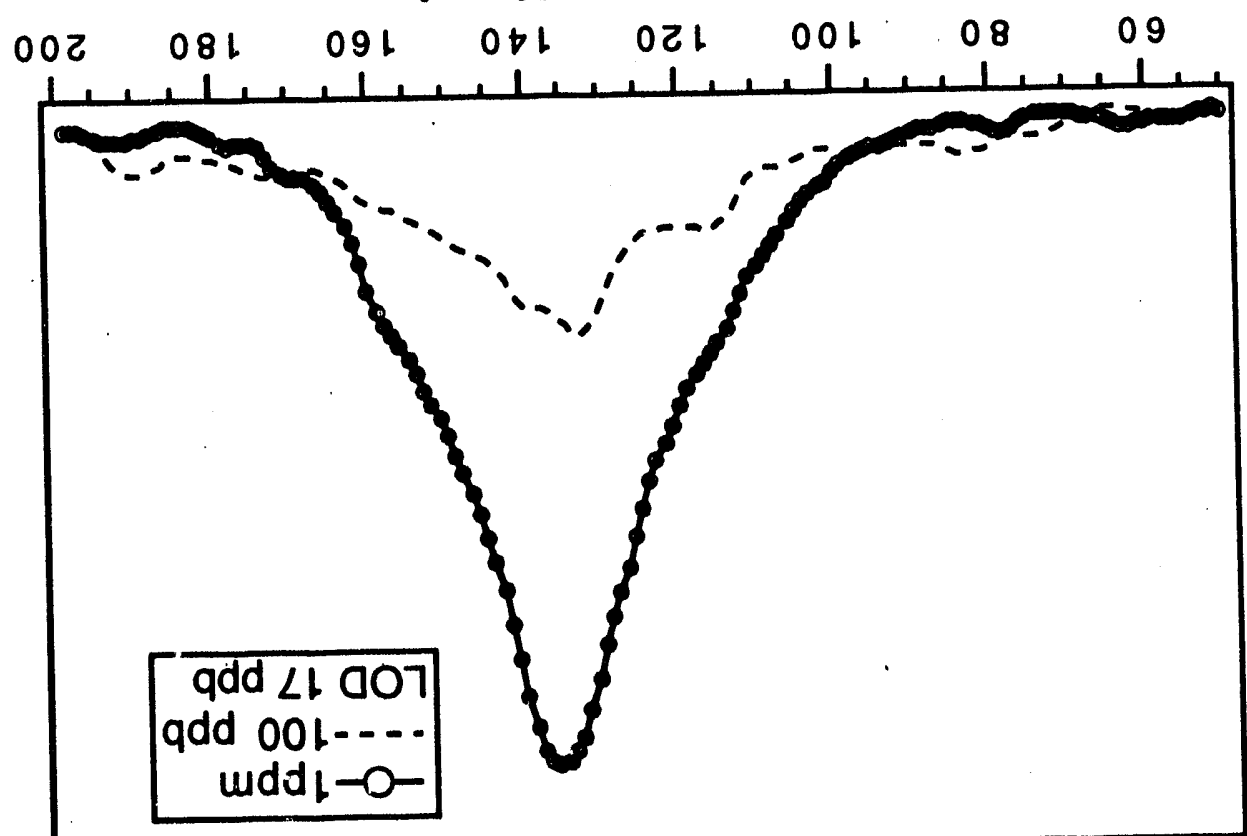

0
0
0
0
0
0
$\frac{1}{0}$
$\frac{1}{0}$
$\frac{0}{2}$ 
The interferometer and associated equipment used to monitor the dye laser performance was replaced this quarter with a pulsed wavemeter (Burleigh Model PLSA 3500). Although the device was a prototype and the software was still under deveiopment, this wavemeter provided better monitoring of dye laser performance than did the Fabry-Perot interferometer - diode array detector we used previously. The new wavemeter was able to display the laser longitudinal mode structure in realtime, which should facilitate dye laser alignment and tuning.

\section{MODIFIED HEAT-PIPE OVEN FOR HIGH-TEMPERATURE SPECTROSCOPY}

\section{Puroose:}

We have been developing a high-temperature heat-pipe oven for use in testing spectroscopic techniques for safeguards monitoring. One reason for our interest in heat-pipe ovens is the ease with which high-resolution spectroscopy can be performed in them. This makes it possible to measure atomic energy levels, isotope shifts, and hyperfine splittings very accurately.

\section{Progress:}

We reported earlier (April 1-June 30, 1991 Quarterly Report) on anomalous line shapes in the Doppler-free saturated absorption spectra of samarium obtained using our modified heat-pipe oven for metal vaporization. We attributed these line shapes to a splitting of the spectroscopic lines by a magnetic field (the Zeeman effect) generated by the heating element of the oven. We have returned to this system with the goal of confirming this explanation and then redesigning the heater to eliminate the effect.

Earlier, we showed that the anomalous line shapes could be removed by turning off the power to the heater as the laser frequency was scanned across an absorption peak. In this quarter we looked at the line shapes as a function of voltage applied to the heater. As before, it was not possible to do the entire experiment at lower voltages since a low voltage resulted in insufficient vapor density to obtain a spectrum.

Therefore, in this experiment, the voltage was held at its normal operating value ( $40 \mathrm{~V}$ ) while the laser frequency was scanned. When the transition was approached, the voltage was lowered to the required value. After the transition was passed, the voltage was returned to $40 \mathrm{~V}$. The results for the $\mathrm{Sm}-152$ isotope, which has no hyperfine splitting, are shown in Figure 3. We find that the applied voltage produces two broad signals, one on either side of the original peak location. A crossover dip appears at the line center. The separation between the two broad signals increases linearly with the applied voltage. This finding is consistent with Zeeman splitting since the Zeeman effect is directly proportional to the magnetic field strength. If the solenoid configuration of our heater is producing a magnetic field, this field strength will be directly proportional to the current flowing through the heater, which in turn will be directly proportional to the applied voltage. 


\section{Samarium-152 Saturated Absorption}

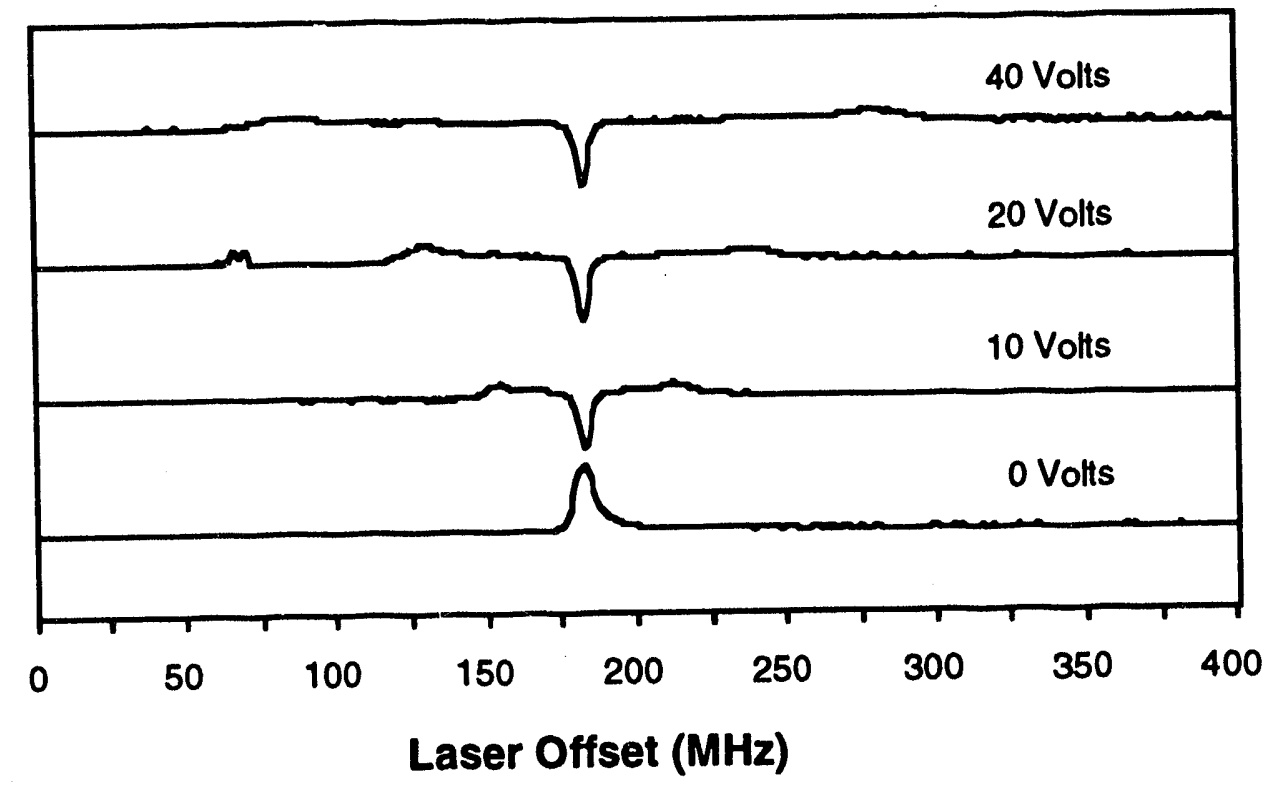

Figure 3. Saturated absorption spectra of $\mathrm{Sm}-152$ near $570.675 \mathrm{~nm}$ as a function of the voltage applied to the heater. As the transition was approached the voltage was lowered from 40 volts to the indicated value.

Zeeman splitting results in energy levels that lie at both higher and lower energies than the zero-magnetic field level. The energy level ordering is reversed by reversing the magnetic field. With the alternating current used in our heater, the magnetic field is continuously varying in magnitude and changing direction. Therefore, the energy level splittings are continuously shifting. To eliminate this source of spectral congestion, a DC power supply was obtained for the heater. A spectrum taken using this power supply is shown in Figure 4.

Under these conditions, a large amount of structure is present. This should be a single peak. Moreover, the Zeeman effect alone cannot account for the large number of peaks seen. Given the values of the total angular momentum of the states involved; $\mathrm{J}=1$ for the lower state, $\mathrm{J}=0$ for the upper state, we should see a maximum of three peaks. We currently do not have an assignment for all the observed peaks.

Another test to establish whether the splitting is due to the Zeeman effect is to use circularly polarized light. Then, depending on the sense of rotation of the polarized light, either the left or right side of this spectrum should disappear; reversing the magnetic field will switch the side of the spectrum that is present. Figure 5 shows the effect on the spectrum, taken with circularly polarized light, of reversing the leads to the heater, which changes the direction of current flow and hence the direction of the magnetic field. The step in the spectrum, due to unresolved splittings, moves from one side of the crossover dip to the other. This behavior is consistent with the Zeeman effect. 


\section{Sm-152 Saturated Absorption}

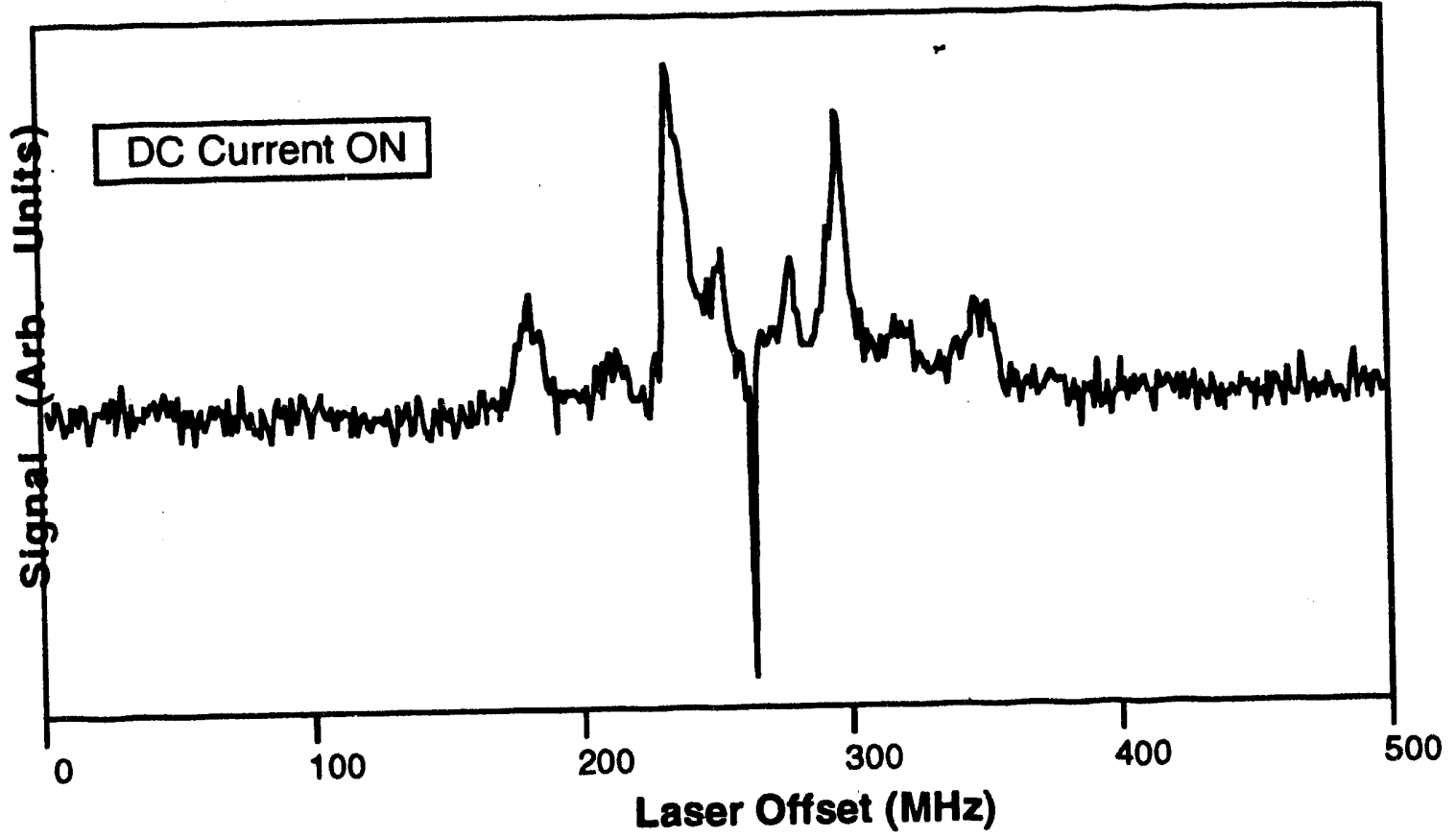

Figure 4. Saturated absorption spectrum of Sm-152 near $570.675 \mathrm{~nm}$ taken with a DC voltage of $33 \mathrm{~V}$ applied to the heater.

Except for the unexpectedly large amount of structure that appears in Figure 4, the above findings confirm the assignment of the structure in the Doppler-free saturated absorption spectra of samarium in the modified heat-pipe oven to Zeeman splitting produced by the heating element. Attempts were undertaken to reduce this perturbation by redesigning the heating element. The current design is simply a coil of tantalum wire extending down the heating region of the oven. Our first approach was to fold a long piece of tantalum wire in half and then wrap this folded wire into a coil. In this configuration, successive turns in the coil carry current in opposite directions. We hoped that this would result in a cancellation of any generated magnetic fields. A spectrum obtained with this heater is shown in Figure 6. Although there is perhaps some improvement, it is seen that this design was not entirely successful.

The next approach was to run the heater wire up and down the length of the oven, with no coiling, for a total of three round trips. The wire was encased in straight eight-inch long by $1 / 16$ th inch OD ceramic tubing for electrical insulation. The open ends of the tubing, where the wire reversed direction and was exposed, were covered with a hightemperature adhesive that was also used to hold the lengths of tubing together, side by side, in a semicircle. This adhesive has a maximum operating temperature of $1400{ }^{\circ} \mathrm{C}$, which is now the high-temperature limit for the modified heat-pipe oven. This design eliminated the solenoid configuration and was successful in eliminating all measurable Zeeman splitting. A high-resolution scan of the Sm-152 transition is shown in Figure 7. 


\section{Sm-152 Saturated Absorption}

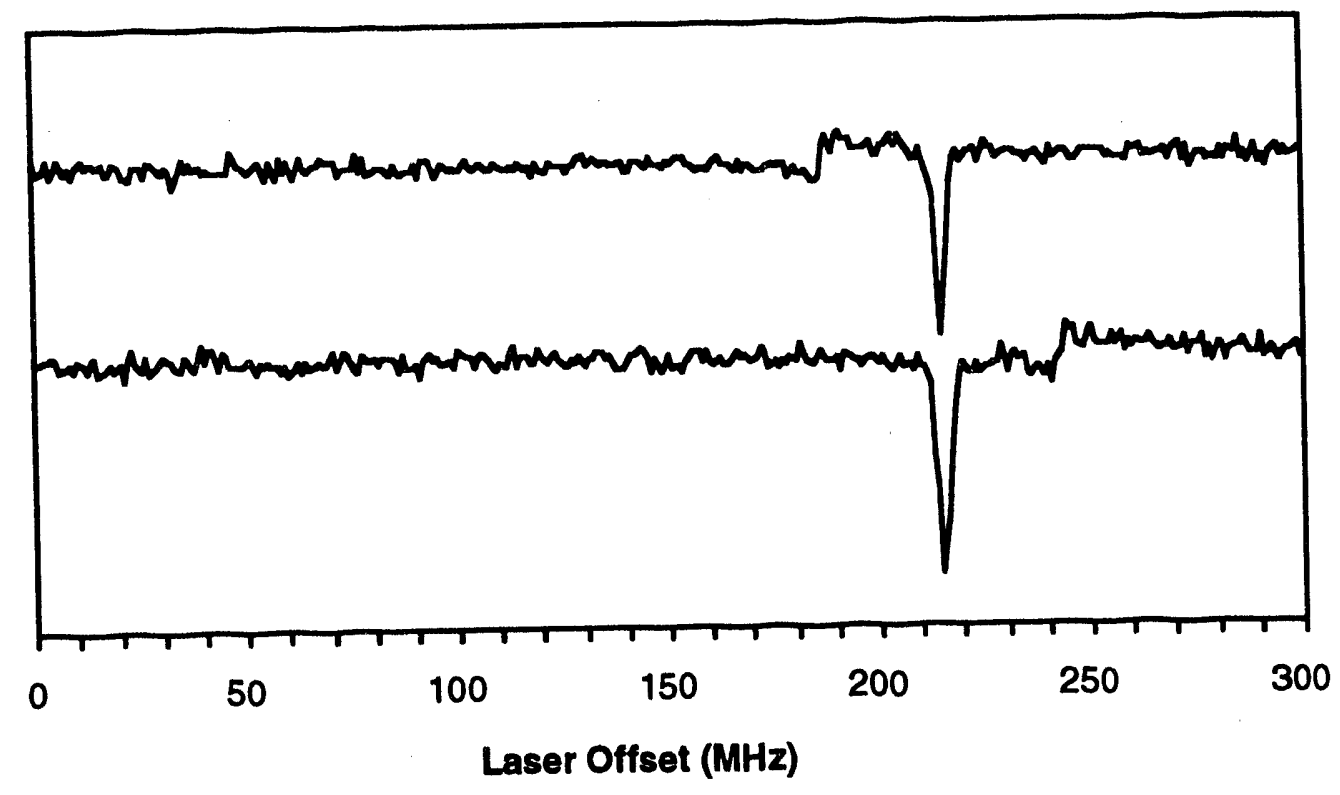

Figure 5. Saturated absorption spectra of Sm-152 at $570.675 \mathrm{~nm}$ taken with a circularly polarized probe beam. Direction of current flow through the modified heatpipe oven and direction of any generated magnetic field was reversed in lower scan.

\section{Sm-152 Saturated Absorption}

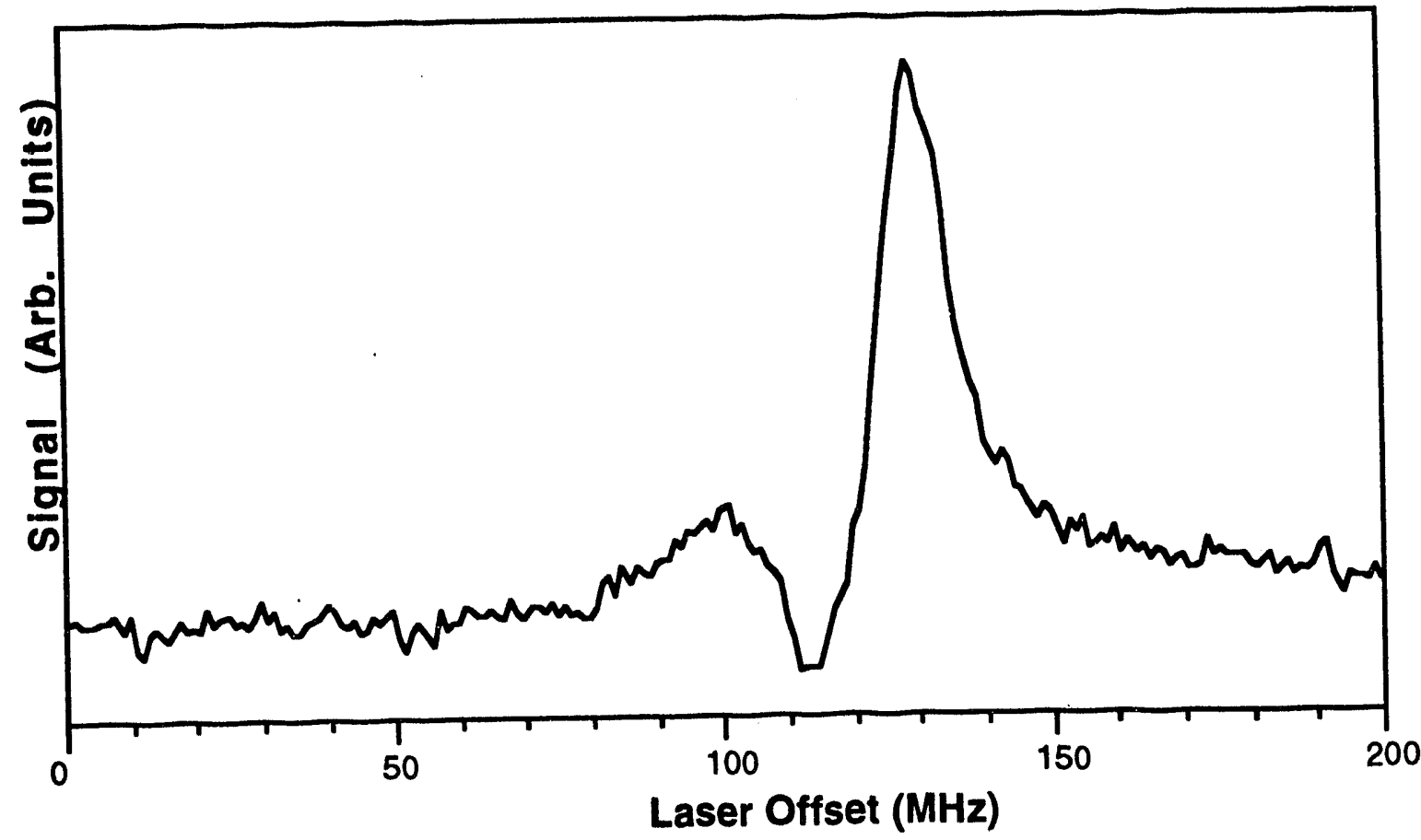

Figure 6. Saturated absorption spectrum of $\mathrm{Sm}-152$ at $570.675 \mathrm{~nm}$ using a heating element in which current flows in opposite directions in successive turns of the coil. 


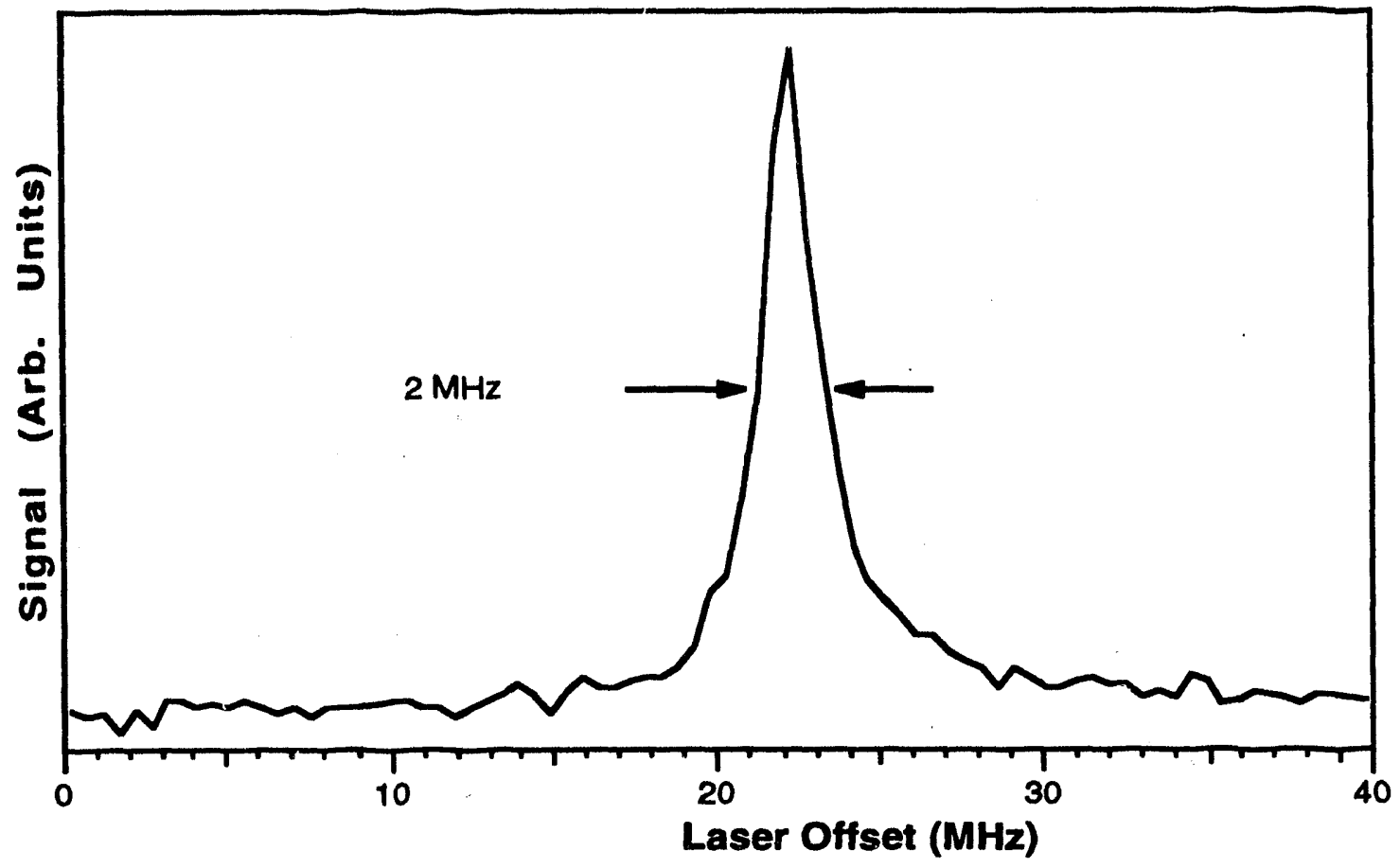

Figure 7. Doppler-free saturated absorption spectrum of Sm-152 near $570.675 \mathrm{~nm}$ taken using the new heating element (see text) showing no detectable splitting.

This peak has a full width at half maximum of roughly $2 \mathrm{MHz}$. We measured the bandwidth of the laser to be $2.5 \mathrm{MHz}$ using a spectrum analyzer with a resolution of $1.2 \mathrm{MHz}$. Thus the peak widths now appear to be limited by the bandwidth of the laser. Figure 8 shows the complete samarium transition at $570.675 \mathrm{~nm}$ taken with the new heater in both Doppler-free and Doppler limited mode. High-resolution scans of the hyperfine splittings in the two odd atomic mass number isotopes are shown in Figure 9. 


\section{Samarium Absorption Spectra}

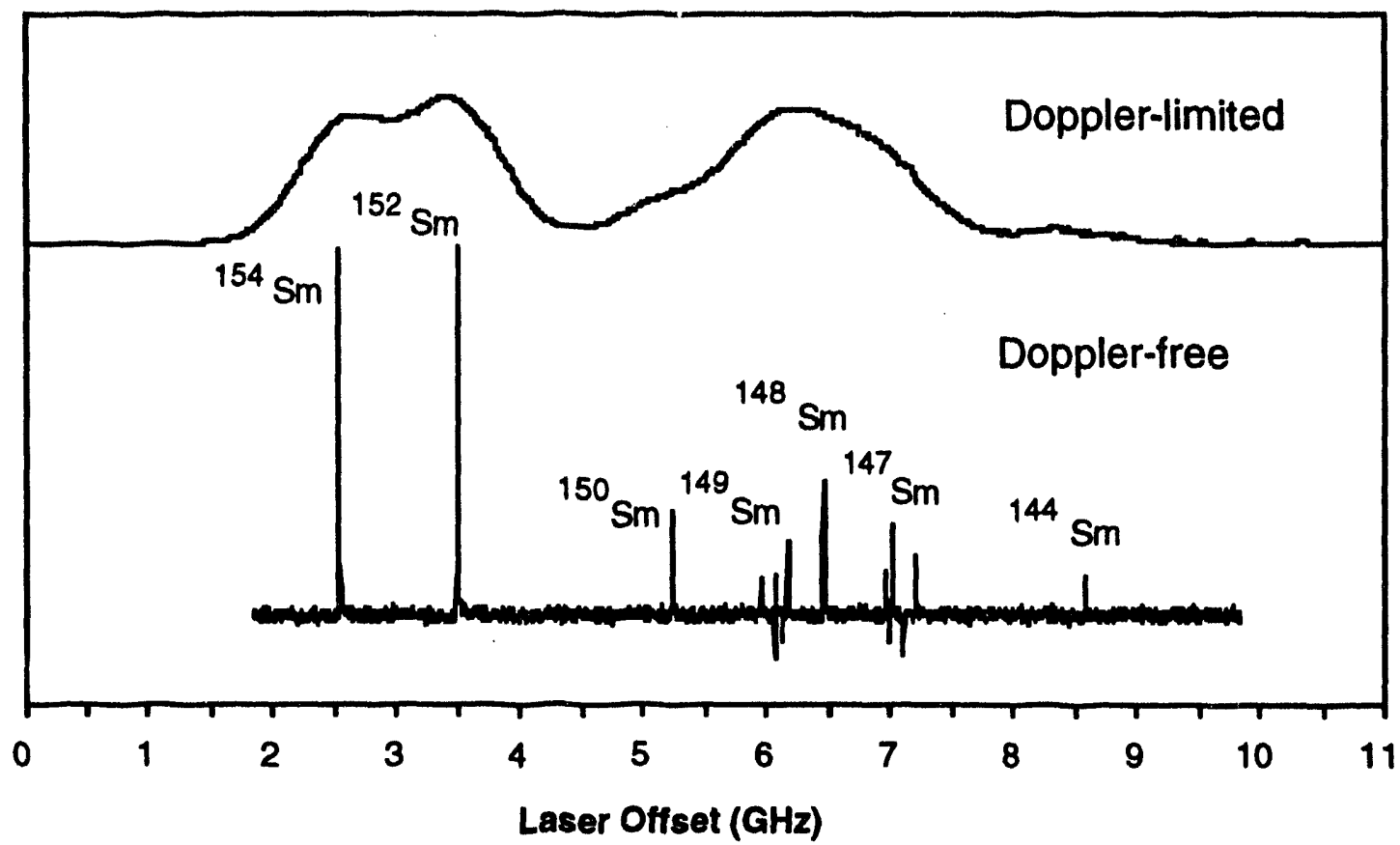

Figure 8. Spuctra of the full samarium transition at $570.675 \mathrm{~nm}$ taken with the new heating element (see text). The top trace is a normal absorption spectrum taken with a high-resolution laser in which peak widths are determined by Doppler broadening. The lower trace is a Doppler-free saturated absorption spectrum.

\section{Future Progress:}

This essentially completes this phase of development of a high-temperature heat-pipe oven. We now have an oven capable of operation at temperatures up to $14000^{\circ} \mathrm{C}$, compared to a maximum operating temperature of $700^{\circ} \mathrm{C}$ for commercially available units. By eliminating the ceramic adhesive, this temperature could be raised to $1900{ }^{\circ} \mathrm{C}$. Spectra taken using this oven for sample vaporization are free of any perturbations, measurable with a $2 \mathrm{MHz}$ bandwidth laser, that are attributable to the oven. The oven will therefore be useful for high-resolution spectroscopic studies of materials whose vapor pressure can be raised to roughly $10^{-4}$ torr at temperatures less than $1400^{\circ} \mathrm{C}$.

One limitation of the current design is the absence of any mechanism for returning material that has condensed in the cooler regions of the tube to the hot central region for re-evaporation. Thus, this oven is not a true heat-pipe. Samples are consumed in a relatively short period; roughly two hours with minimal heating to produce a spectroscopic signal. In this latest design, with the heating wires encased in ceramic tubes, it will be possible to incorporate a tantalum mesh to provide the wicking action of a heat-pipe oven. 

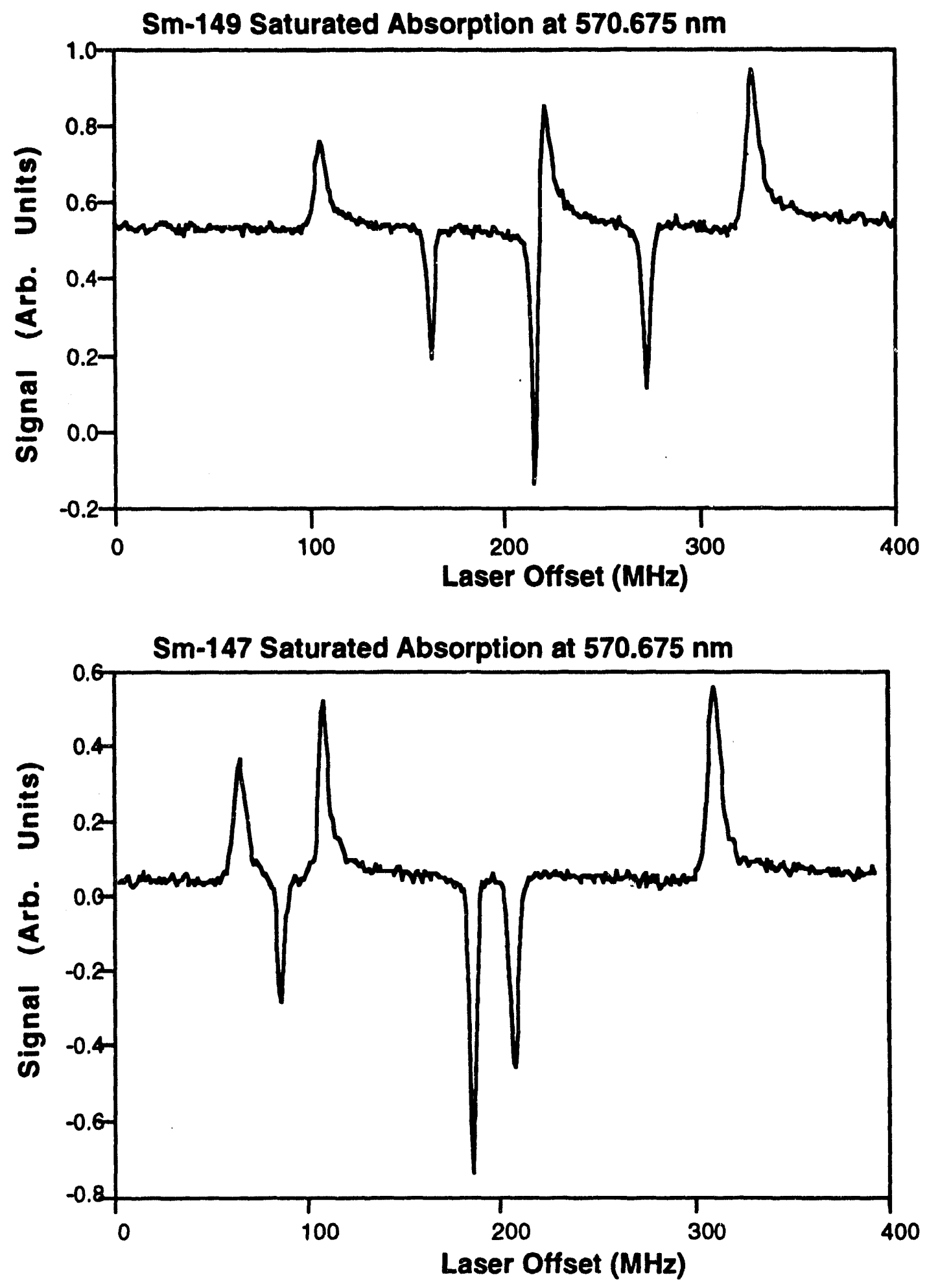

Figure 9. Doppler-free saturated absorption spectrum of Sm-147 and Sm-149 near $570.675 \mathrm{~nm}$ taken using the newly configured heat pipe oven. 


\section{OPTICAL SPECTROSCOPY OF ACTINIDE IONS IN CONDENSED PHASES}

\section{Purpose:}

This work includes the development of new selective organic complexing agents to permit the ultratrace detection of actinide materials in complex solutions and crystalline hosts by low-temperature laser luminescence \& absorption spectroscopy.

\section{Progress:}

Although we are encountering difficulty in synthesizing $4 H$-Pyran-2,6-dicarboxylic acid, work continues on the complexes of uranium and dipicolinic acid. A low resolution room temperature spectrum of the dipicolinate salt of uranyl ion was measured. This was accomplished by suspending a sample, sealed in a capillary tube, inside the ICP torch box and exciting luminescence with a low pressure mercury lamp. The spectrum shows that, even at room temperature, the bandwidths of the uranyl ion in this compound are quite narrow (FWHM $<5 \mathrm{~nm}$ ) when compared to a typical molecular emission spectrum. The ability to excite strong luminescence with an unfocused low pressure $\mathrm{Hg}$ lamp shows this to be a highly luminescent compound.

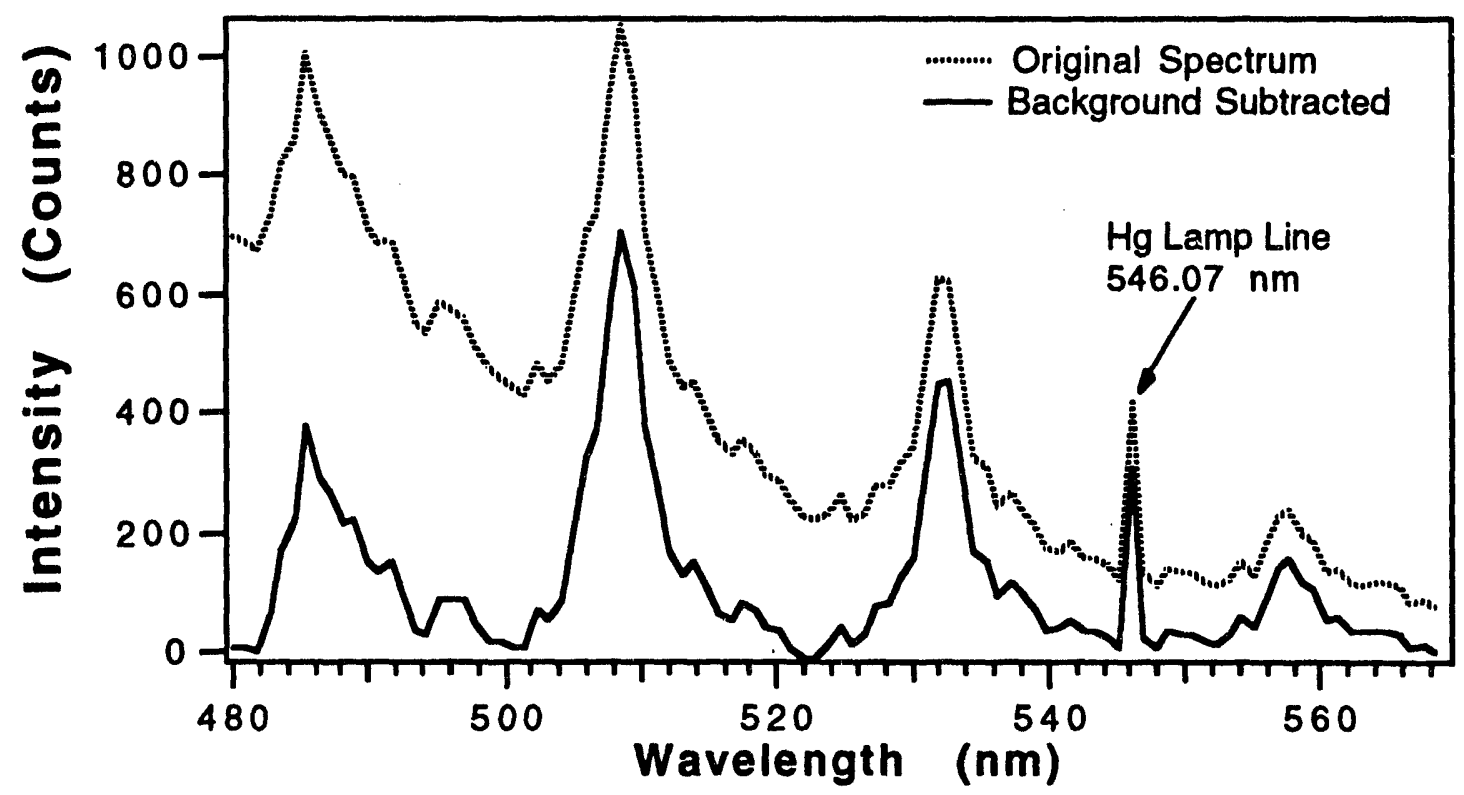

Figure 10. Room temperature luminescence spectrum of $\left.\mathrm{Cs}_{2}\left[\mathrm{UO}_{2} \text { (dipicolinate) }\right)_{2}\right] \cdot \mathrm{X}$ $\mathrm{H}_{2} \mathrm{O}$. 


\section{APPLICATIONS OF DIODE LASERS}

\section{Purpose:}

Optical absorption spectroscopy has recently been applied to the measurement of $\mathrm{Pu}$ in fuel dissolver solutions (Kuno, et al., "Input Plutonium Accountability Analysis in a Reprocessing Plant by Spectrophotometry Using Internal Standards," Proc. 31st INMM Annual Meeting, July 15-18, 1990, pgs. 817-821). No chemical separation of Pu from $U$ was required. This measurement, achieved with non-laser light sources, was not capable of isotopic resolution. It required relatively concentrated solutions (only a factor of 20 dilution of dissolver solution with $\sim 1 \mathrm{~g} / \mathrm{L}$ Pu was used) that have the potential of damaging the quartz optical absorption cell through the formation of radiation-induced color centers.

This work investigates the application of diode lasers to the real-time, optical spectroscopic measurement of actinides. Laser-based optical spectroscopy can result in improved detection limits, which permit the use of lower analyte concentrations, and isotopic selectivity. Diode lasers confer additional advantages: low cost, ease of use, narrow single-mode line widths, and wavelength tunability. It is also notable that most actinides have a rich spectrum with transitions from low-lying levels occurring in the red and near-infrared regions of the spectrum. These wavelengths can be reached with well-developed AIGalnP and AIGaAs laser diodes. The shortcomings of the diode laser, e.g., mode hops, low power, and narrow wavelength range coverage, still limit the application of diode lasers. We are developing diode laser systems that improve temporal stability and spectral resolution. In addition, a diode laser system with fiber optics is being developed for the real-time, remote monitoring of radioactive materials for field and on-site measurements.

\section{Progress:}

Development of a diode laser system for monitoring actinides was initiated. To improve temporal stability and spatial resolution, we designed a modular diode laser system with four separate units: the diode laser unit, the beam monitoring unit, the sampling unit, and the data acquisition unit. Each unit has unique functions critical to maintaining the long-term quality of analytical measurements.

The diode laser unit consists of a laser diode, laser housing, power supply, and thermoelectric temperature controller. The wavelength stability of the diode laser depends upon the stability of the power supply and the temperature controller. The diode laser wavelength and peak intensity vary as the case temperature and/or diode current vary. In fact, the fine tuning of the diode laser wavelength is normally accomplished by varying the diode current.

The beam monitoring unit is used for determining diode laser mode structure, linewidth, wavelength, and power. This unit consists of a wavemeter, spectrum analyzer or confocal etalon, and power meter. A rough guide to the laser wavelength is provided by a Burleigh wavemeter (resolving power $=10^{6}$, resolution $=0.01 \mathrm{~cm}^{-1}$ ); more accurate wavelength measurements are achieved by reference to $I_{2}$ molecular lines or known atomic lines. The spectrum analyzer can measure the mode structure and the linewidth of diode lasers. Typically, most diode lasers have $10 \cdot 30 \mathrm{MHz}$ 
linewidths, which are more than adequate for the resolution of actinide isotope shifts. The interferogram of a Mistubishi AIGaAs diode laser (ML-64110N) has been measured with a Burleigh 2GHz FSR spectrum analyzer (SA-200). The linewidth at 30 $\mathrm{mW}$ output power was 20-25 MHz (Figure 11). For high-resolution spectroscopy, a $150 \mathrm{MHz}$ or $300 \mathrm{MHz}$ confocal etalon can be used for wavelength calibration. Finally, a sensitive power meter is required to normalize LIF or optogalvanic signals produced by diode lasers. Such a sensor will be obtained in the near future.

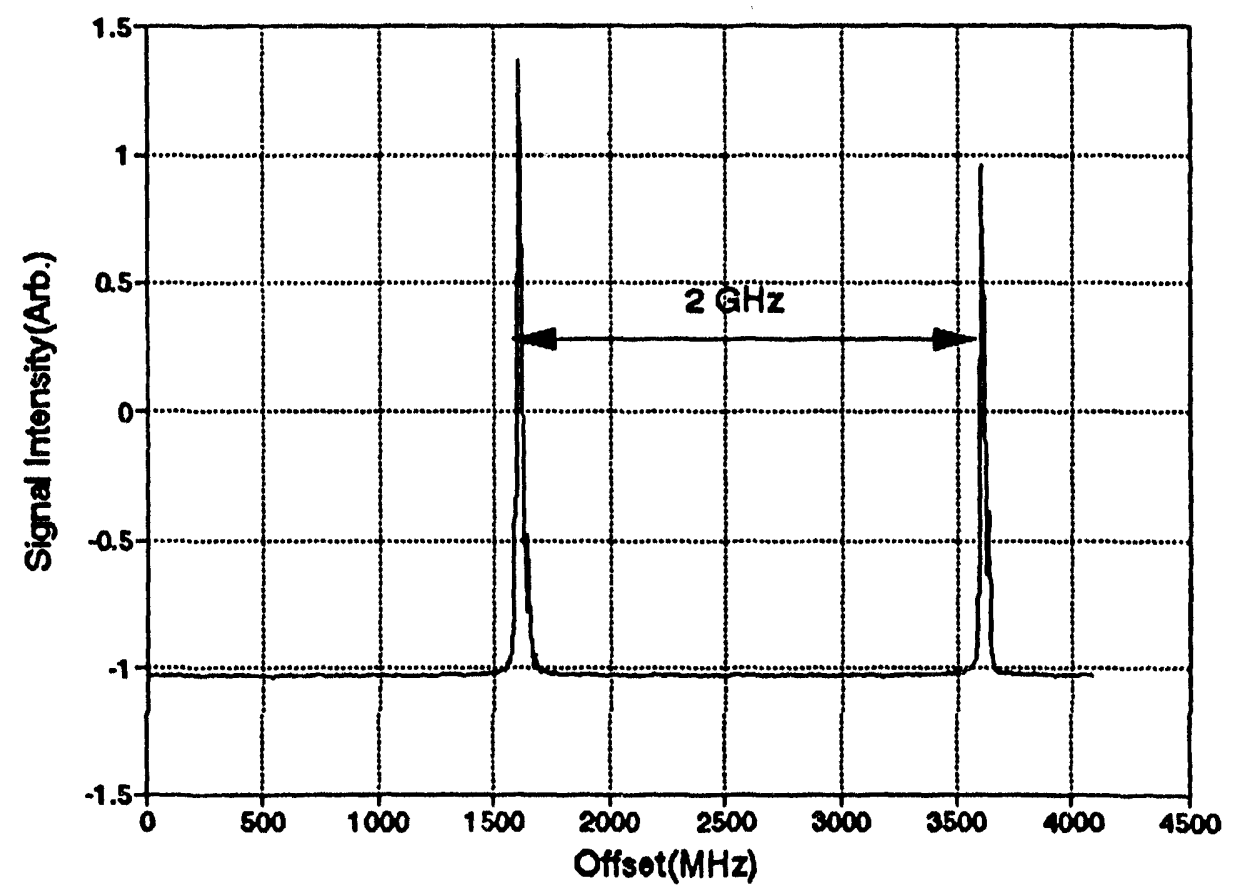

Figure 11 Interferogram of Mitsubishi AlGaAs diode laser (ML64110N). Data was collected by a $2 \mathrm{GHz}$ FSR spectrum analyzer (Burleigh SA-200).

The diode laser system can be easily modified for different experiments by changing the sampling unit. The available sampling units include an electron-gun vaporizer, an ICP, a collection of hollow cathode lamps, a heat pipe oven, and a newly designed glow discharge atomizer. The modified glow discharge atomizer will be designed to monitor radioactive materials and can be easily adapted for use with diode lasers.

Data acquisition is accomplished using a computer-assisted signal processing systcm. For continuous wave diode lasers, a chopper is used to modulate the laser and phase sensitive electronics are used for signal detection. The data acquisition unit includes computers, related software, choppers, lock-in amplifiers, and a GPIB/IEEE board. The software can read a signal from a lock-in amplifier and scan the wavelength of a diode laser simultaneously. 


\section{Optogalvanic Spectroscopy}

Doppler-limited optogalvanic spectroscopy of uranium and thorium in commercial hollow cathode tubes was investigated. The diode laser was scanned through the electronic transition by applying a repeated triangle wave function to the current modulation input of the laser power supply; calibration of the spectrum was accomplished by knowing the scan length and using the spacing between alternate peaks in the repeated scan. A mechanical chopper at $3 \mathrm{KHz}$ was used to modulate the $\mathrm{cw}$ diode laser beam and this beam was directed onto the cathode. The discharge current between the anode and cathode changed as uranium or thorium atoms in the hollow cathode tube absorbed laser light. The optogalvanic signal was monitored with a lock-in amplifier through a $5 \mathrm{k} \Omega$ ballast resistor placed in series with the hollow cathode lamp and $0.1 \mu \mathrm{F}$ capacitor. The experimental setup is shown in Figure 12.

Uranium atoms were detected by optogalvanic spectroscopy using diode lasers. This marked the first observation of an actinide element using a diode laser source. Uranium has three naturally occuring isotopes, but the commercial hollow cathode lamp we used was constructed with depleted uranium. We could not measure the isotopic abundance of uranium with the commercial lamp. Relatively strong transitions in the 770-850 nm wavelength range were measured. The initial electronic states of uranium atoms ranged from $620 \mathrm{~cm}^{-1}$ to $7326 \mathrm{~cm}^{-1}$.

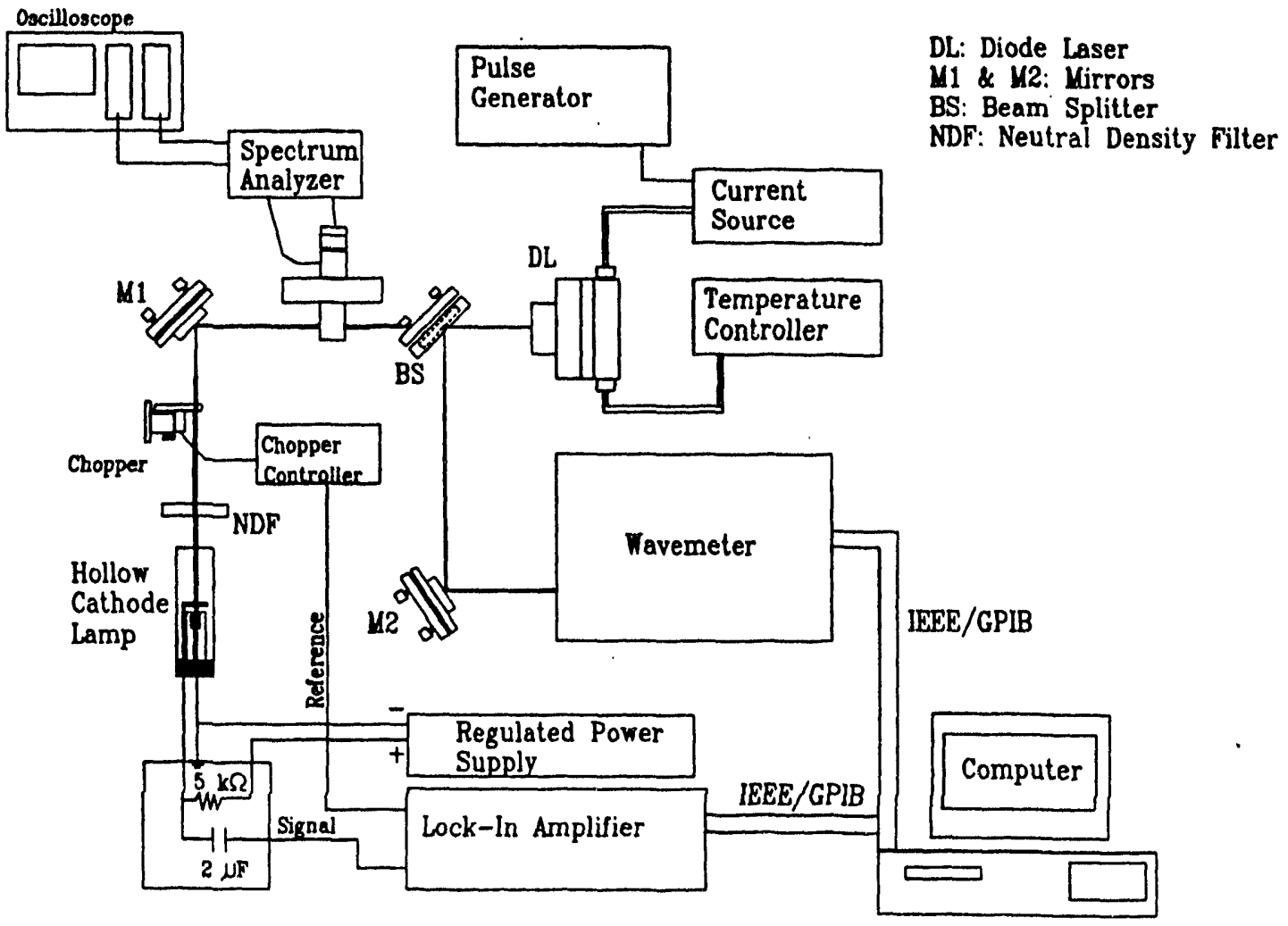

Figure 12 Schematic diagram of optogalvanic spectroscopy using a diode laser. 
This indicates that the glow discharge may efficiently populate high-lying electronic states of uranium atoms. The uranium optogalvanic spectrum of the $620 \mathrm{~cm}^{-1} .->$ $13463 \mathrm{~cm}^{-1}$ transition is shown in Figure 13.

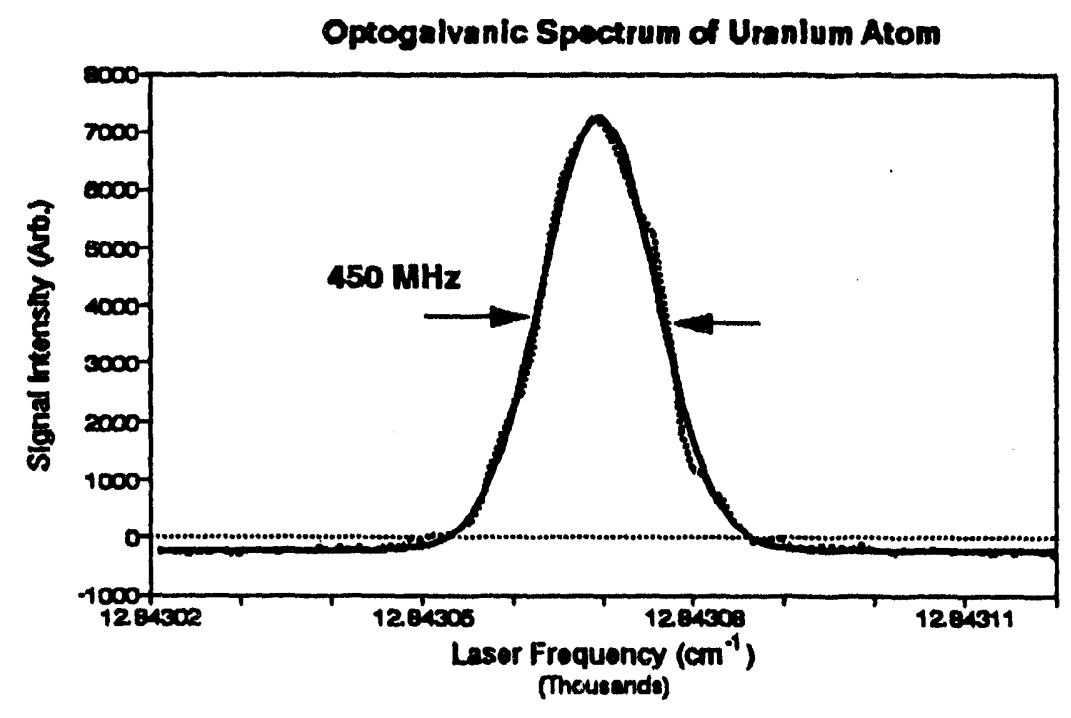

......m Real Data Gaussian Fih

Figure 13 Diode laser optogalvanic spectrum of $U$ atoms in a hollow cathode lamp.

A least-squares fit of the uranium peak to a Gaussian line shape was calculated. The fit yielded a $U$ linewidth at full width at half maximum (FWHM) of $450 \mathrm{MHz}$. Broadening of the uranium peak was mainly due to the Doppler effect (i.e., thermal broadening). The Hitachi diode laser (HL7801E) used had a bandwidth of less than $25 \mathrm{MHz}$. Another promising transition of uranium atoms occurs at $860.8 \mathrm{~nm}\left(0 \mathrm{~cm}^{-1}-\rightarrow\right.$ $\left.11613 \mathrm{~cm}^{-1}\right)$. This transition has an oscillator strength roughly five times greater than the one at $778.4 \mathrm{~nm}$.

Thorium atoms were detected in a commercial hollow cathode lamp in the same way as used for uranium detection. Thorium has only one naturally occurring isotope. We detected three spectral lines of thorium atoms, at $781.777 \mathrm{~nm}, 833.045 \mathrm{~nm}$, and $841.673 \mathrm{~nm}$. The initial states of these lines ranged from $0 \mathrm{~cm}^{-1}$ to $10414 \mathrm{~cm}^{-1}$. Again, the glow discharge effectively populated high-lying electronic states of atoms, which isn't commonly observed in spectra from graphite furnace and electron-gun heaters. The optogalvanic spectrum of the $0 \mathrm{~cm}^{-1} \rightarrow 11877.8392 \mathrm{~cm}^{-1}$ transition of thorium is shown in Figure 14. 


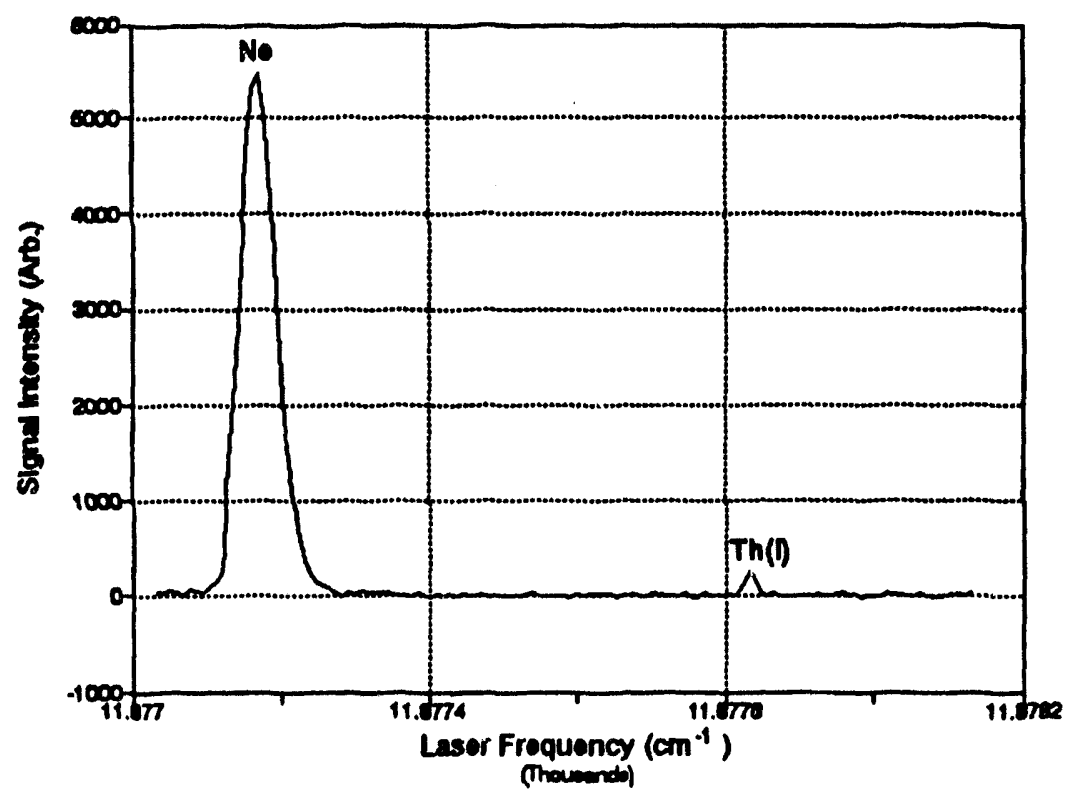

Figure 14 Diode laser optogalvanic spectrum of thorium in a commercial hollow cathode lamp. The strong peak at $11877.18 \mathrm{~cm}^{-1}$ is due to neon and the weak peak at $11877.84 \mathrm{~cm}^{-1}$ is due to thorium.

Two peaks appeared in the spectrum. The large peak at $11877.18 \mathrm{~cm}^{-1}$ was due to neon and its linewidth (FWHM) was $1.4+1-0.3 \mathrm{GHz}$. The weak thorium peak appeared at $11877.84 \mathrm{~cm}^{-1}$ and had a $445+/-26 \mathrm{MHz}$ linewidth. The calculated ratio of the Doppler linewidths of the two peaks agreed with the experimental value. The optogalvanic signal of thorium atoms was weaker than the uranium signal. Laser power and lamp current dependencies were investigated. There was a linear relationship between the lamp current and the optogalvanic signal. However, the intensity of the optogalvanic signal was not linearly dependent on the diode laser power. For example, the relationship between the signal intensities of the thorium line at $841.673 \mathrm{~nm}$ and the uranium line at $776.185 \mathrm{~nm}$ and the lamp current and diode laser power was studied. Both line intensities were linearly dependent upon the lamp current, but the thorium line saturated at laser powers greater than $3 \mathrm{~mW}$, which demonstrated that the relatively low-power diode laser used in this work was capable of saturating an electronic transition. The results are summarized in Figures $15 \& 16$. 


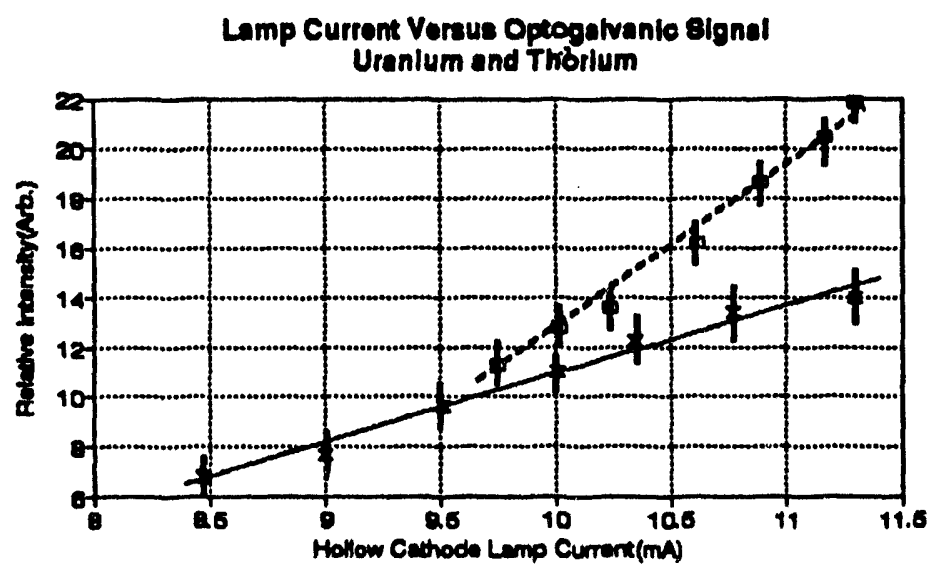

- Uranlum a Thorlum

Figure 15 Plot of lamp current vs. $U$ optogalvanic signal at $776.185 \mathrm{~nm}$ and Th optogalvanic signal at $841.673 \mathrm{~nm}$.

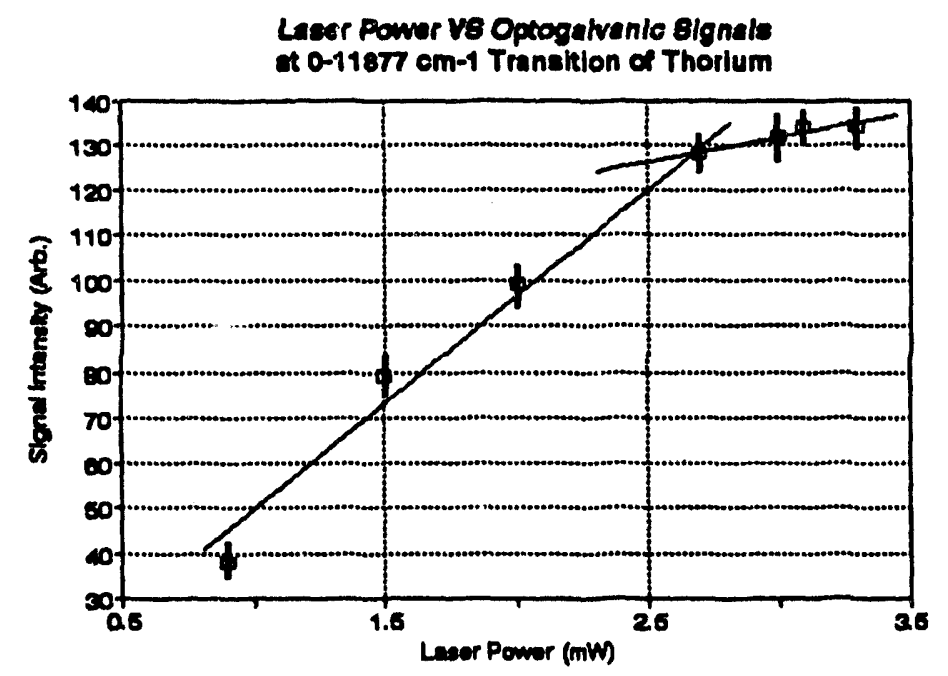

Figure 16 Plot of diode laser power versus thorium signal at $841.673 \mathrm{~nm}$.

The diode laser optogalvanic spectrum of the rubidium D2 line $(780.023 \mathrm{~nm})$ was measured and the hyperfine splittings of rubidium were observed. The study of the $\mathrm{Rb}(\mathrm{I}) \mathrm{D} 2$ line has been reported [J. Lawrenz and K. Niemax, Spectrochim. Acta 44B, 155 (1989)]. Two other $\mathrm{Rb}$ lines at $775.765 \mathrm{~nm}$ and $775.943 \mathrm{~nm}$ were detected but the hyperfine splittings were not resolved. 
Laser-Induced Fluorescence of Gadolinium Vapor

The Doppler-free fluorescence spectrum of gadolinium vapor in an atomic beam was excited by a diode laser. Resonance and non-resonance fluorescence was collected by a $0.25 \mathrm{~m}$ monochromator at $90^{\circ}$ to the laser beam and the collimated atomic vapor. A red sensitive photomultiplier tube (Hamamatsu 758) was used to detect the fluorescence. The experimental setup is shown in Figure 17.

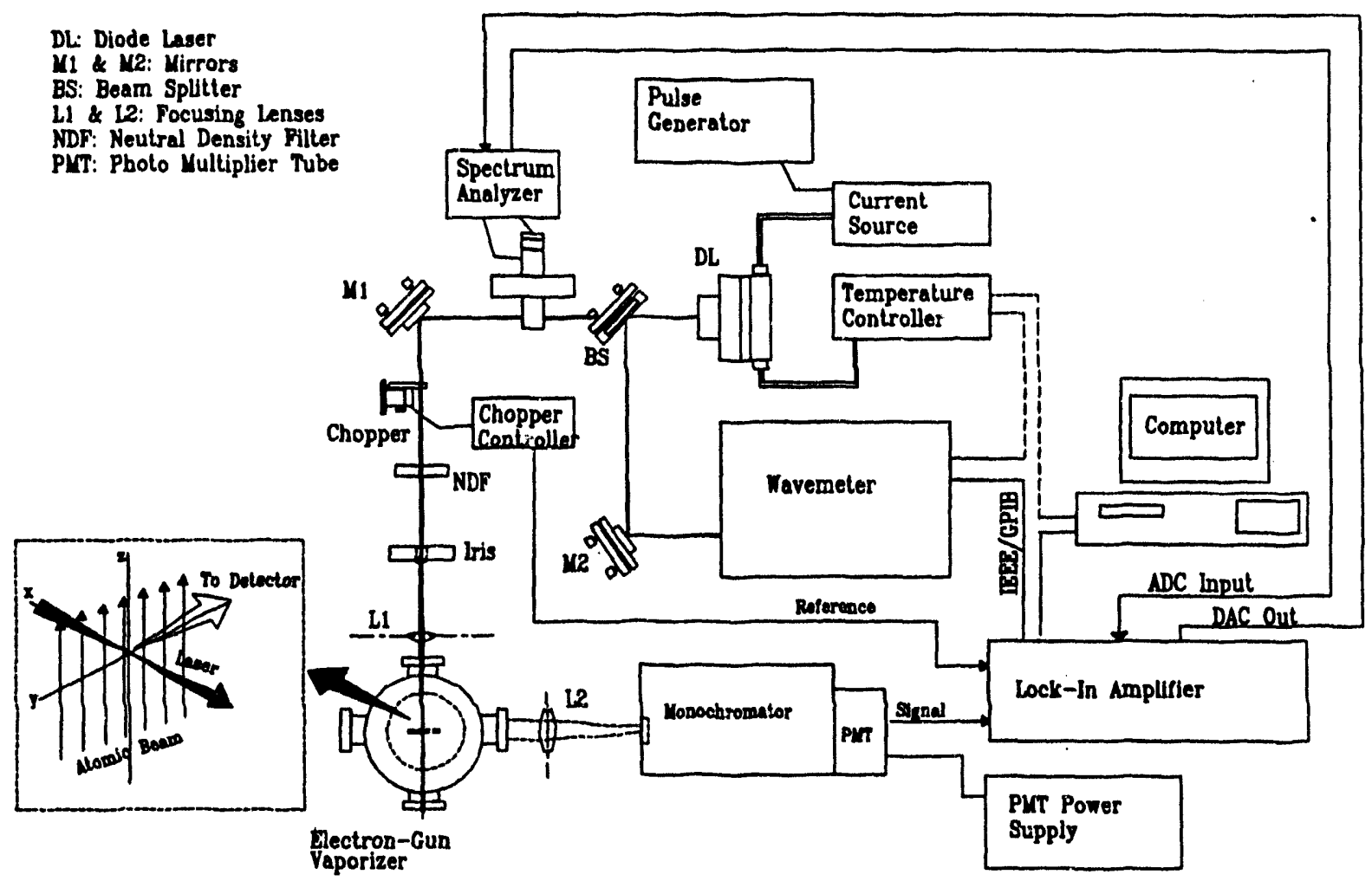

Figure 17 Experimental setup for the diode laser induced fluorescence spectroscopy of gadolinium vapor.

Gadolinium has seven isotopes (nominal natural abundances are indicated in parentheses): $152 \mathrm{Gd}(0.2 \%),{ }^{154} \mathrm{Gd}(2.18 \%),{ }^{155} \mathrm{Gd}(14.80 \%),{ }^{156} \mathrm{Gd}(20.47 \%)$, $157 \mathrm{Gd}(15.65 \%),{ }^{158} \mathrm{Gd}(24.84 \%)$, and ${ }^{160} \mathrm{Gd}(21.86 \%)$. Odd $\mathrm{Gd}$ isotopes have nonzero nuclear spins $(I=3 / 2)$ and have electronic spectral transitions that are split by hyperfine effects. The LIF spectrum of gadolinium vapor was quite complicated and difficult to analyze due to the many isotopic splittings and hyperfine structures. However, the spectra due to the even isotopes were relatively easy to assign. We investigated two relatively strong transitions that could be probed by diode lasers. These transitions are at $773.350 \mathrm{~nm}\left(999 \mathrm{~cm}^{-1}\left({ }^{9} \mathrm{D}_{5}{ }_{5}\right)-{ }^{2} 13926 \mathrm{~cm}^{-1}\left({ }^{9} \mathrm{P}_{4}\right)\right)$ and at $774.930 \mathrm{~nm}\left(533 \mathrm{~cm}^{-1}\left({ }^{9} \mathrm{D}^{\circ}\right) \cdots 13434 \mathrm{~cm}^{-1}\left({ }^{9} \mathrm{P}_{3}\right)\right)$. The LIF spectrum of gadolinium vapor at $773.350 \mathrm{~nm}$ is shown in Figure 18. 


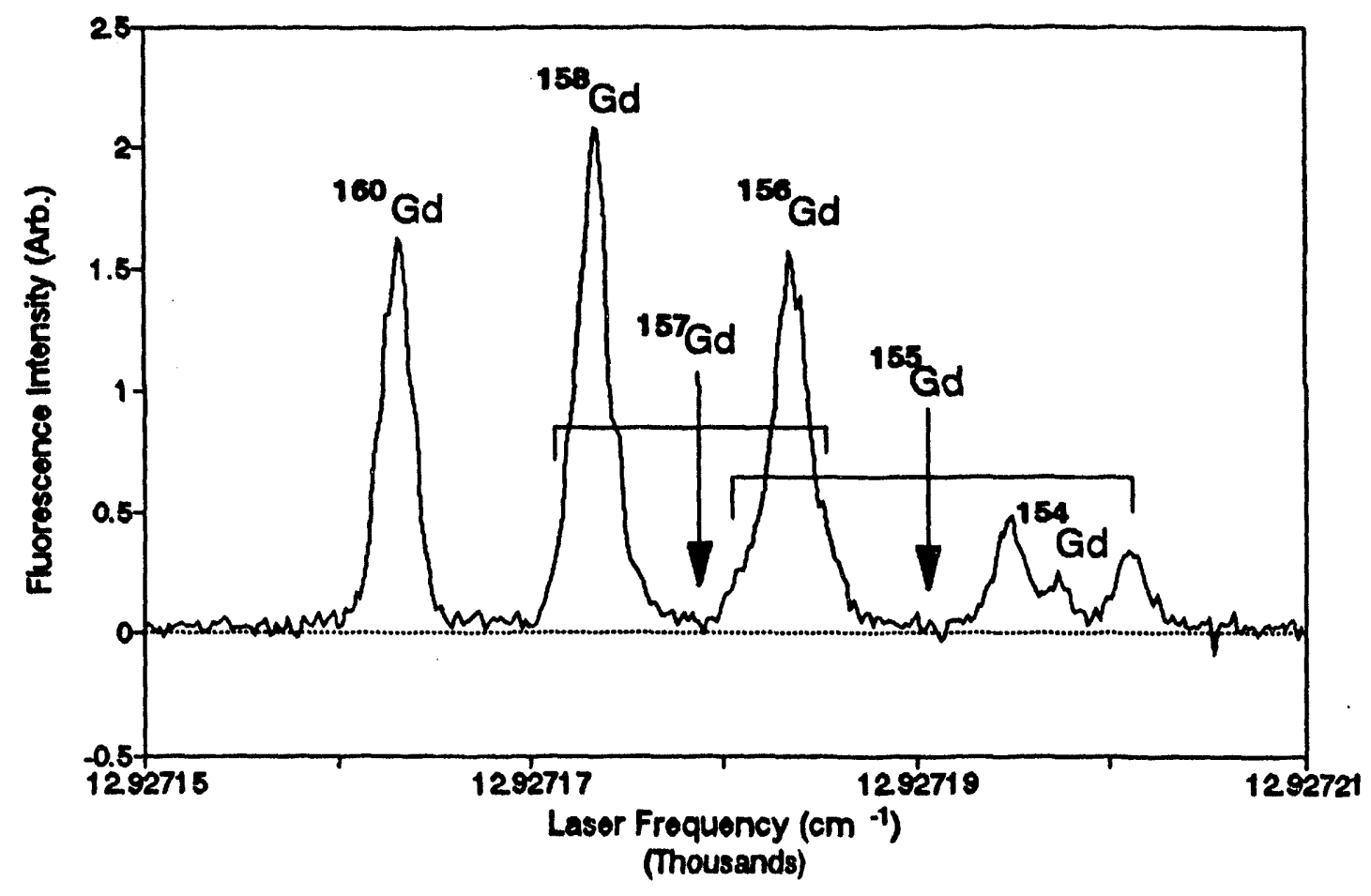

Figure 18 Diode laser induced fluorescence spectrum of Gd vapor at $773.350 \mathrm{~nm}$.

Each odd isotope has four hyperfine components in the lower state and four hyperfine components in the excited state. A total of nine transitions involving these hyperfine components will occur. Only two of these transitions are expected to be strong. Even isotopes do not suffer hyperfine splitting and only a single peak for each even isotope appears. Clear assignments for the even isotopes can thus be made without difficulty. The fluorescence bandwidth of $160 \mathrm{Gd}$ was $60+1-5 \mathrm{MHz}$ and the total spectral range was around $1.2 \mathrm{GHz}$. The diode laser did not have sufficient resolution to resolve all of the isotopic and hyperfine components. The laser induced fluorescence spectrum of gadolinium vapor at $774.930 \mathrm{~nm}$ was similar to the spectrum at $773.350 \mathrm{~nm}$ but the isotope shifts at $774.930 \mathrm{~nm}$ were smaller than those at $773.350 \mathrm{~nm}$. Isotopic ratio and abundance measurements could not be achieved due to the complexity of the spectrum and the uncompensated temporal variation of signal intensity as the laser wavelength was varied.

\section{Future Studies:}

Development of the diode laser system will continue. To improve the temporal and spectral resolution of the diode laser unit, we will order an ultra-low noise power supply and temperature controller. In addition, a $300 \mathrm{MHz}$ confocal etalon and a sensitive laser power meter will be ordered during the next quarter. We will initiate the design of a modified glow discharge atomizer that can ibe used for the quantitative analysis of actinides using high resolution spectroscopy with diode laser sources. Optogalvanic spectroscopy using diode lasers will continue and we will evaluate the 
merits of the technique for monitoring actinides. The laser induced fluorescence spectrum of yttrium vapor will be generated using red diode lasers. We will also investigate the application of diode lasers for remote spectroscopy using fiber optics. 


\section{DISTRIBUTION LIST}

Mr. Edward J. McCallum, Director

Office of Safeguards and Security, SA-10

U.S. Department of Energy

Washington, D.C. 20585

Mr. David Crawford, Chief

Materials Control and Accountability Branch, SA-124

Office of Safeguards and Security

U.S. Department of Energy

Washington, D.C. 20585

Mr. Jerry Howell, Director

Field Operations Division, SA-13

Office of Safeguards and Security

U.S. Department of Energy

Washington, D.C. 20585

Dr. G. Dan Smith, Chief

Planning and Technology Development Branch, SA-134

Office of Safeguards and Security

U.S. Department of Energy

Washington, D.C. 20585

Mr. David Jones, Director

Policy, Standards, and Analysis Division, SA-12

Office of Safeguards and Security

U.S. Department of Energy

Washington, D.C. 20585

Patent Office, USDOE

Chicago Field Office

9800 South Cass Avenue

Argonne, IL 60439

USDOE-TIC

Oak Ridge National Laboratory

P.O. Box 62

Oak Ridge, TN 37830

Ms. Beth Weiser

Public Affairs \& Information

Ames Laboratory

lowa State University

Ames, IA 50011 
Dr. Martin Edelson

Ames Laboratory

lowa State University

Ames, IA 50011

Prof. T. J. Barton, Director

Ames Laboratory

lowa State University

Ames, IA 50011

Mr. Lowell Mathison

Ames Laboratory

lowa State University

Ames, IA 50011

Dr. C. Bingham

New Brunswick Laboratory

9800 South Cass Avenue

Argonne, IL 60439

Dr. D. C. Camp

Associate Division Leader

Lawrence Livermore National Laboratory

P.O. Box 808, L-232

Livermore, CA 94550

Mr. J. G. Douglas

Westinghouse Hanford Co.

P.O. Box 1970

Richland, WA 99352

Mr. C. E. Pietri

Physical Science Administrator

Chicago Field Office

U.S. Department of Energy

9800 South Cass Avenue

Argonne, IL 60439 

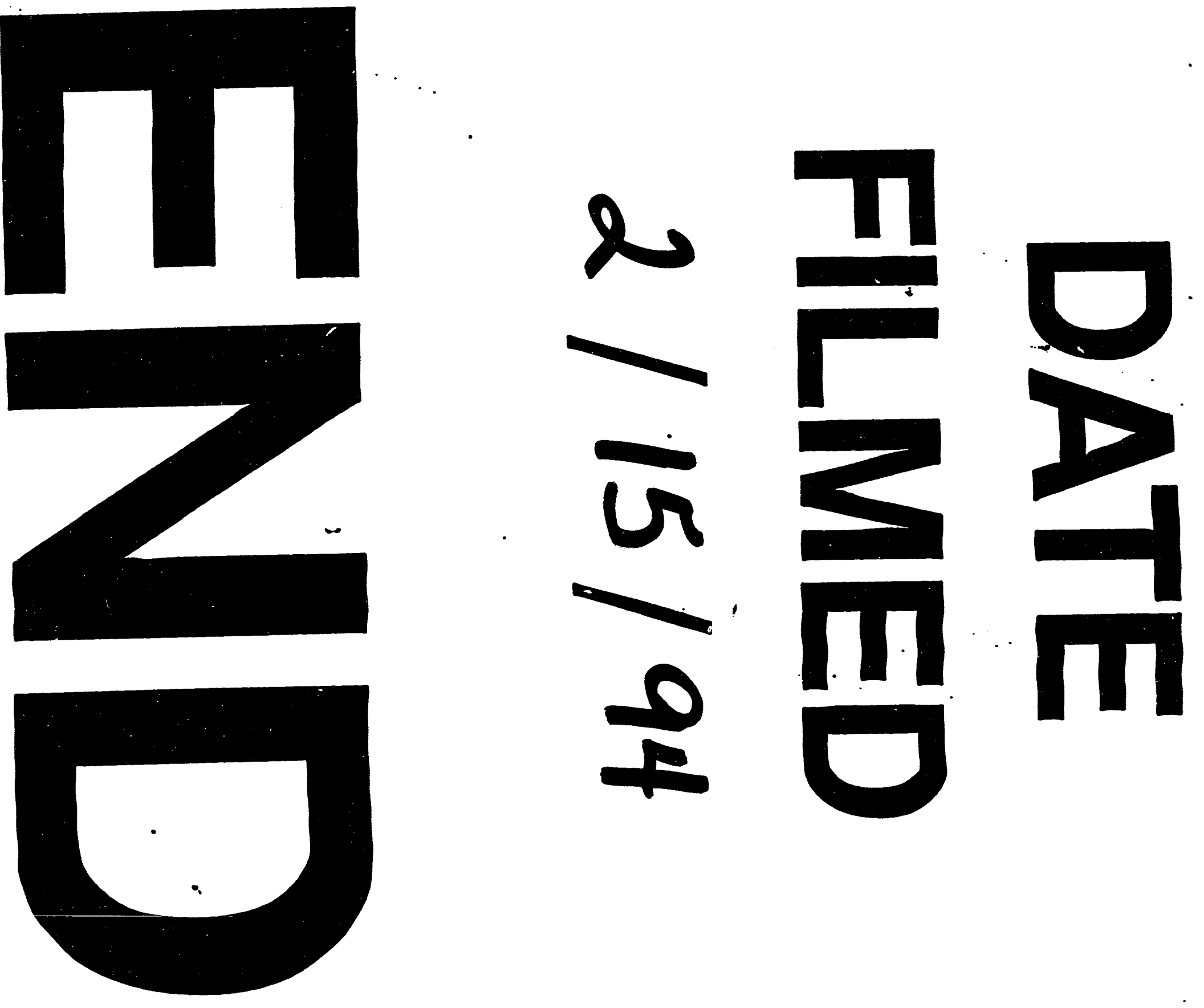